

\title{
Ana Dili Eğitimi Dergisinde Yayımlanan Makalelerin Bibliyometrik Analizi*
}

\author{
Beytullah KARAGÖZ** \\ imran KOÇ ARDIÇ***
}

\begin{abstract}
Öz
Bilgi aktarımı ve paylaşımı sürecinde alana özgü bilimsel dergilere büyük ihtiyaç bulunmaktadır. Ana Dili Eğitimi Dergisi (ADED), Türkçe eğitimi alanındaki araştırmalara ev sahipliği yapan hakemli bilimsel bir dergidir. Ana Dili Eğitimi Dergisi, 2013 yılından bu yana kesintisiz olarak yayın hayatını sürdürmektedir. Dergi yılda dört sayı olarak yayımlanmaktadır. Derginin tüm sayılarına Dergipark üzerinden açık erişim politikasıyla ücretsiz olarak ulaşılabilmektedir. Bu çalışmada 2013-2018 yılları arasında Ana Dili Eğitimi Dergisinde yayımlanan makalelerin bibliyometrik özellikler bakımından incelenmesi amaçlanmıştır. Dergide yayımlanan makaleler bibliyometrik yaklaşımla incelenerek çeşitli açılardan karşılaştırmalar yapılmış ve bazı sonuçlara ulaşılış̧ır. Bu bağlamda Ana Dili Eğitimi Dergisi toplam makale sayısı, makalelerin yayın dili, makalelerin sayfa sayıları, makalelerin yazarlık durumları, yazarların çalışıkları kurumlar, yazarların unvanı, makalelerin değerlendirme süresi, makalelerdeki kaynak türleri, makalelerdeki kaynakça sayılarının dağılımı, makalelerin konu dağııımı açııından incelenmiştir. Araştırmanın bazı bulguları şunlardır: Dergide en çok yayın yapılan akademik yayın türü makaledir. Makalelerin tamamına yakını Türkçedir. Dergide en çok makale yayımlanan yı 2018 ( $f=68)$ olmuştur. Makale sayfa sayılarının \%34'ü 16-20 sayfa aralığında yoğunlaşmaktadır. Dergideki yayınlar çoğunlukla iki yazarlıdır. Dergiye katkı sağlayan yazarların çoğunluğu "Dr. Öğr. Üyesi/Yrd. Doç. Dr." unvanlıdır. Ana Dili Eğitimi Dergisine en çok katkı yapan araştırmacılar Gazi Üniversitesi, Milli Eğitim Bakanlığı ve Mustafa Kemal Üniversitesi adreslidir. Dergide en sık atıf yapılan kaynak türü, dergidir (makale).
\end{abstract}

Anahtar kelimeler: Bilimsel dergi, Ana Dili Eğitimi Dergisi, bibliyometrik özellikler.

\section{Bibliometric Analysis of the Articles Published in Journal of Mother Tongue Education}

\begin{abstract}
There is a great need for field-specific scientific journals in the process of information transfer and sharing. Journal of Mother Language Education (JOMTE) is a peer-reviewed scientific journal that hosts research in the field of Turkish education. The Journal of Mother Language Education has been published continuously since 2013. The journal is published four times a year. All issues of the journal are available free of charge through Dergipark's open access policy. The aim of this study is to investigate the bibliometric characteristics of the articles published in the Journal of Mother Language Education between 2013-2018. The articles published in the journal were examined with bibliometric approach and comparisons were made in various respects and some results were obtained. In this context, the total number of articles, the publication language of the articles, the page numbers of the articles, the authorship status of the articles, the institutions where the authors work, the title of the authors, the period of evaluation of the
\end{abstract}

\footnotetext{
*Bu makale 13-14 Aralık 2018 tarihleri arasında düzenlenen V. Yıldız Uluslararası Sosyal Bilimler Kongresi'nde sunulan bildiri özetinin genişletilmiş halidir.

**Dr. Öğr. Üyesi, Tokat Gaziosmanpaşa Üniversitesi, Eğitim Fakültesi, Türkçe ve Sosyal Bilimler Eğitimi Bölümü, Tokat, beytullah.karagoz@gop.edu.tr, ORCID: 0000-0003-2966-8226

*** Öğretmen, Milli Eğitim Bakanlığı, Sivas, imrenim_88@hotmail.com, ORCID: 0000-0003-3859-5081
} 
articles, number of source types in articles, number of bibliography in articles, number of bibliography in articles, topic distribution of articles, authorsin the Journal of Mother Tongue Education are examined in terms of the authors who published the most articles. According to the findings of the study, the most widely published type of academic publication in the journal is the article. Almost all articles are in Turkish. The most published article was in 2018. It was determined that the range of pages with the maximum number of pages of articles is $16-20$ pages. The majority of the publications in the journal are two authors. Most of the academic titles of the authors of the articles published in the journal are Assistant Professor and Associate Professor Doctor. In addition, articles in different academic titles were also included in the journal. In the Journal of Mother Tongue Education, it is determined that the most published institutions are Gazi University, Ministry of National Education and Mustafa Kemal University. The most commonly referred source in the journal is the article.

Keywords: Scientific journal, Journal of Mother Tongue Education, bibliometric properties.

\section{Giriş}

Bilimsel bilgi üretiminde ve yayılmasında ana kanallardan biri de bilimsel dergilerdir. Bilimsel dergiler bilim insanlarının deney, gezi ve gözlem sonucu elde ettiği bilgi ve bulguları akademik ortam ile paylaşmasını sağlar. Başka bir deyişle bilim adamları bilimsel inceleme ve araştırma sonucunda ürettiği bilgiyi bilimsel dergilerde yayımlar. Bu sayede bilim dünyasında bir iletişim ve etkileşim alanı ortaya çıkar. Dolayısıyla bilim dünyası ve bilimsel alışverişin devamı için, akademik dergiler belirleyici önemdedir.

"Bibliyometrik araştırmalarda belgelerin ya da yayınların belirli özellikleri analiz edilerek bilimsel iletişime ilişkin çeşitli bulgular elde edilmektedir" (Al ve Coştur, 2007: 144). "Bibliyometrik analiz herhangi bir alana ilişkin yayınlanmış çeşitli kaynakların gelişim düzeyinin tespit edilmesi açısından önemli bir yere sahiptir" (Hotamışlı ve Erem, 2014: 16). Garfield'e (1972) göre "bilimsel iletişim araçlarının kullanım oranlarının belirlenmesinde, ilgili literatürdeki en etkin yazarların belirlenmesinde ve tek başına bir derginin değerlendirilmesine yönelik olarak kullanılabilmektedir" (aktaran Yalçın, 2010). Bu doğrultuda çalışma Türkçe eğitimi alanında ilk olma özelliği taşıyan Ana Dili Eğitimi Dergisinde yayımlanan makalelerin bibliyometrik açıdan değerlendirilmesine yöneliktir.

Yayın hayatına 2013 yılında başlayan Ana Dili Eğitimi Dergisi (ADED) yılda dört sayı olarak (Kış/Ocak, Bahar/Nisan, Yaz/Temmuz, Güz/Ekim) yayımlanan uluslararası hakemli bir dergidir. Ana Dili Eğitimi Dergisi (ADED) ULAKBiM TR Dizin, DOAJ, Index Copernicus, Modern Language Association (MLA), ERIH PLUS gibi ulusal ve uluslararası indekslerde taranmaktadır. Türkçe eğitimi alanında yayımlanan ilk ve tek bilimsel dergi olan Ana Dili Eğitimi Dergisinde yayımlanan makalelerin bibliyometrik açıdan incelenmesi, Türkçe eğitimi akademik alanındaki gelişme ve eğilimleri belirlemek açısından önemli görülmektedir.

Önceki çalışmalar incelendiğinde farklı disiplinlerdeki bilimsel dergilerin bibliyometrik analizini amaçlayan araştırmalar olduğu görülmektedir (Al, Soydal ve Yalçın, 2010; Beşel ve Yardımcıoğlu, 2017; Birinci, 2008; Çetinkaya Bozkurt ve Çetin, 2016; Çiçek ve Kozak, 2012; Hotamışlı 
ve Erem, 2014; Karagöz ve Kozak, 2014; Polat, Sağlam ve Sarı, 2013; Tsay ve Shu, 2011; Taşkın ve Çakmak, 2010; Ulu ve Akdağ, 2015; Yalçın, 2010). Buna karşın alanyazında Türkçe eğitimi bilim alanında ilk bilimsel dergi olan Ana Dili Eğitimi Dergisini bibliyometrik özellikler açısından inceleyen herhangi bir araştırmaya rastlanmamıştır.

Bu çalışma, Ana Dili Eğitimi dergisinde yayımlanan makalelerin bibliyometrik profilini belirlemek ve derginin zaman içindeki gelişim sürecini ortaya çıkarmak amacıyla gerçekleştirilmiştir. Türkçe eğitimi alanında beş yıldır akademik bir kararlıııla yayın hayatına devam eden dergideki makalelerin bibliyometrik parametrelerle incelenmesi derginin eğilimlerine ilişkin edinilen bilgilerin hem alanyazına hem de araştırmacılara katkı sağlayacağı düşünülmektedir.

\section{Yöntem}

\section{Araştırmanın Modeli}

Bu araştırma, nitel bir durum çalışmasıdır. Durum çalışmasında "amaç, belirli bir duruma ilişkin sonuçlar ortaya koymaktır. Nitel durum çalışmasının en temel özelliği bir ya da birkaç durumun derinliğine araştırılmasıdır" (Yıldırım ve Şimşek, 2011: 77). Çalışmada Ana Dili Eğitimi Dergisinin bibliyometrik profili derinlemesine bir yaklaşımla ortaya konulmak istendiği için, çalışma durum çalışması olarak desenlenmiştir.

\section{Verilerin Toplanması ve Analizi}

Ana Dili Eğitimi Dergisi TR Dizin Sosyal ve Beşeri Bilimler Veri Tabanı Dergi Listesinde yer alan 372 dergiden biridir. Çalışmada 2013-2018 yılları arasında Ana Dili Eğitimi dergisinde yayımlanan toplam 254 akademik yayın bibliyometrik göstergeler bakımından incelenmiştir. Derginin tüm sayılarına Dergipark üzerinden ulaşılmıştır. Derginin arşiv bölümünde yayımlanan 254 yayının tamamına PDF formatında erişilmiştir. 2013-2018 yılları arasında ADED'de yayımlanmış olan akademik yayınlar 10 bibliyometrik parametre altında incelenerek kategorize edilmiştir. Veriler birbirinden bağımsız iki araştırmacı tarafından toplanmış ve karşılaştırma yapılış̧tır. Sapma gösteren veriler tekrar gözden geçirilerek nihai rakamlara ulaşıımaya çalışılmıştır. Bu süreçten sonra elde edilen veriler sayısallaştırılarak tablolara aktarılmıştır.

Araştırmada veriler bir soru formu ile toplanmıştır. Bu formun oluşturulması sürecinde alanyazına başvurulmuştur (Al ve Coştur, 2007; Al, 2012; Al, Soydal ve Yalçın, 2010; Armutlu ve Arı, 2010; Birinci, 2008; Cevizkaya, İlsay ve Avcıkurt, 2014; Hotamışlı ve Erem, 2014; Özel ve Kozak, 2012; Taşkın ve Çakmak, 2010; Varışoğlu, Şahin ve Göktaş, 2013; Yalçın, 2010). Form çalışmanın amacına uygunluğu ve dilsel özellikleri bakımından üç Türkçe eğitimi ve üç eğitim bilimi alanında uzman araştırmacıların görüşüne sunulmuştur. Değerlendirmecilerin verdiği yanıtlar arasında tutarlıık gözetilerek forma son şekli verilmiştir. 
Formda yer alan araştırma soruları şunlardır:

1. Ana Dili Eğitimi dergisinde yayımlanan akademik yayınların türlerine göre dağılımı nasıldır?

2. Ana Dili Eğitimi dergisinde yayımlanan makalelerin yayın dili nedir?

3. Ana Dili Eğitimi dergisinde yayımlanan makalelerin sayfa sayılarının durumu nasıldır?

4. Ana Dili Eğitimi dergisinde yayımlanan makalelerin yazar sayılarının durumu nasıldır?

5. Ana Dili Eğitimi dergisinde yayımlanan makalelerin yazarlarının çalıştıkları kurumların dağılımı nasıldır?

6. Ana Dili Eğitimi dergisinde yayımlanan makalelerin yazar unvan dağılımı nasıldır?

7. Ana Dili Eğitimi dergisinde yayımlanan bir makalenin ortalama değerlendirme süresi nedir?

8. Ana Dili Eğitimi dergisinde yayımlanan makalelerdeki kaynak türlerinin dağılımı nasıldır?

9. Ana Dili Eğitimi dergisinde yayımlanan makalelerin kaynakça sayılarının yıllara göre dağııımı nasıldır?

10. Ana Dili Eğitimi dergisinde yayımlanan makalelerin konularına göre dağılımı nasıldır?

Çalışmanın verileri bibliyometrik analiz tekniği kullanılarak çözümlenmiştir. Bibliyometrik analiz matematik ve istatistiksel yöntemlerin kitaplara ve diğer iletişim araçlarına uygulanmasını sağlayan sayısal analiz yöntemidir (Pritchard, 1969). Başka bir anlatımla bibliyometrik analiz, akademik yayın türlerindeki bibliyografik göstergeleri çözümlemeye yarayan sistematik bir yöntemdir. Bibliyometrik analizle makro seviyede ülkelerin ya da bir disiplinin yayınları analiz edilebilirken, mezo seviyede kurumlar veya mikro seviyede yazarlar üzerinden analizler gerçekleştirilebilmektedir (Yalçın ve Öztürk, 2017). Bu yanıyla bibliyometrik yöntemler yayınların performansını değerlendirmek, yazarları ve kurumları takip etmek, sıralamak ve haritalandırmak için araştırma değerlendirme uygulamasında yüksek kalitede güvenilir ve bilgilendirici veriler sunmaktadır (Özsoy ve Demir, 2018). Aynı zamanda bir derginin bilimsel yönelimi ve dinamizmi ile ulusal ve uluslararası bilim ve teknolojiye katılımı hakkında bilgi sağlar (Van Raan, 2003).

Çalışmada elde edilen veriler, veri toplama aracında belirtilen sıralamaya göre kodlanmış ve belirlenen çerçeveye uygun olarak değerlendirilmiştir. Veriler bu çerçeveye göre işlenerek ulaşılan bulgular tanımlanmış ve yorumlanmıştır. 
İç güvenirliği sağlamak için araştırma raporunun yazım aşamasında metin ile tablo, grafik ve şekiller sürekli karşılaştırmaya tabi tutulmuştur. Bu yaklaşımla veri analiz sürecinin nesnel bir değerlendirmeye temel oluşturması sağlanmaya çalışılmışır. Dış güvenirliği artırabilmek için birinci araştırmacı, çalışma ile ilgili veriyi iki Türkçe eğitimi ve bir ölçme değerlendirme alan uzmanına görüş almak amacıyla göndermiştir. Uzmanlardan gelen dönütler çerçevesinde araştırma raporu üzerinde düzenlemeler yapılmıştır.

\section{Bulgular}

Bu bölümde, Ana Dili Eğitimi dergisinde 2013-2018 yılları arasında yayımlanan makalelerin incelenmesi sonucu elde edilen veriler, verilere ait tablolar ve grafikler yer almaktadır. ADED ile ilgili ulaşılan genel bilgiler ise şu şekildedir:

ADED'de Yayımlanan Makaleler ile Ilgili Bazı Genel Bilgiler

2013-2018 yılları arasında ADED'de yayımlanan makalelerin bazı özellikleri Tablo 1'de gösterilmektedir.

Tablo 1. ADED'de yayımlanan makaleler ile ilgili bazı genel bilgiler

\begin{tabular}{lr}
\hline Toplam Makale Sayısı & $\mathbf{2 5 1}$ \\
\hline Toplam Kitap Tanıtımı Yazısı & $\mathbf{3}$ \\
\hline Makalelerin Ağırıılı Yayın Dili & Türkçe \\
\hline Toplam Sayfa Sayısı & $\mathbf{4 2 5 1}$ \\
\hline Değerlendirme Süresi Belirtilen Toplam Makale Sayısı & $\mathbf{1 8 6}$ \\
\hline Toplam Kurum Sayısı & $\mathbf{7 1}$ \\
\hline Toplam Unvan & $\mathbf{4 0 8}$ \\
\hline Toplam Atıf Sayısı & $\mathbf{7 7 0 4}$ \\
\hline
\end{tabular}

Tablo 1'de çalışma kapsamında bibliyometri ile elde edilen bilgiler yer almaktadır. Tablo incelendiğinde dergide yayımlanan akademik yayın türleri, makalelerde çoğunlukla kullanılan dil, derginin beş yıllık süreçte toplam kaç sayfa makale yayımladığı, değerlendirme süresi bilgisi bulunan makale sayısı, makale yazarlarının toplam unvan sayısı, dergiye katkı sağlayan kurumlar ve kaynakçalarda yer alan toplam atıf sayısı hakkında genel izlenim oluşacaktır.

\section{ADED'de Yayımlanan Akademik Yayın Türleri}

Yılda dört sayı olarak yayımlanan dergide yer alan akademik yayın türlerinin sayılarının yıllara göre dağılımı aşağıdaki tabloda verilmektedir. 
Tablo 2. ADED’de yayımlanan akademik yayın türlerinin yıllara göre dağılımı

\begin{tabular}{crrrrrrrr}
\hline & $\mathbf{2 0 1 3}$ & $\mathbf{2 0 1 4}$ & $\mathbf{2 0 1 5}$ & $\mathbf{2 0 1 6}$ & $\mathbf{2 0 1 7}$ & $\mathbf{2 0 1 8}$ & Toplam & $\%$ \\
\hline Makale & 31 & 30 & 25 & 41 & 56 & 68 & $\mathbf{2 5 1}$ & 99 \\
\hline Kitap Tanıtımı & 1 & - & - & - & 2 & - & 3 & 1 \\
\hline Toplam & 32 & 30 & 25 & 41 & 58 & 68 & $\mathbf{2 5 4}$ & 100 \\
\hline
\end{tabular}

Tablo 2'de 2013-2018 yılları arasında $A D E D$ 'de yayımlanan akademik yayın türlerinin sayısal dağııımları verilmektedir. Dergide yayımlanan toplam yayın sayısının 254 olduğu görülmektedir. Dergide 3 kitap tanıtımı yazısı yer almaktadır. Buna göre $A D E D^{\prime}$ de en çok makale türünde yayın yapılmıştır. En fazla makale 2018 (f=68) yılında yayımlanmıştır. Daha sonra en fazla makale yayımlanan yılların 2017 ( $\mathrm{f}=56)$ ve 2016 ( $\mathrm{f}=41)$ olduğu anlaşılmaktadır. En fazla kitap tanıtımı yayımlanan yıl ise $2017(\mathrm{f}=2)$ olmuştur.

\section{ADED'de Yayımlanan Makalelerin Yayın Dillerinin Yıllara Göre Dağılımı}

Makalelerin yayın dili incelenmiş olup ulaşılan sonuçlar frekans ve yüzde olarak Tablo 3'te gösterilmiştir.

Tablo 3. ADED'de yayımlanan makalelerin yayın dillerinin yıllara göre dağılımı

\begin{tabular}{crrrrrrrr}
\hline & $\mathbf{2 0 1 3}$ & $\mathbf{2 0 1 4}$ & $\mathbf{2 0 1 5}$ & $\mathbf{2 0 1 6}$ & $\mathbf{2 0 1 7}$ & $\mathbf{2 0 1 8}$ & $\mathbf{f}$ & $\mathbf{\%}$ \\
\hline Türkçe & 32 & 29 & 25 & 36 & 57 & 66 & $\mathbf{2 4 5}$ & 96 \\
\hline Ingilizce & - & 1 & - & $\mathbf{5}$ & 1 & 2 & 9 & 4 \\
\hline Toplam & 32 & 30 & 25 & 41 & 58 & 68 & $\mathbf{2 5 4}$ & 100 \\
\hline
\end{tabular}

Tablo 3'e göre dergide yayımlanan makalelerin yayın dilinin Türkçe ( $f=245)$ ve İngilizce ( $f=9$ ) olduğu görülmüştür. Derginin 2013 ve 2015 yıllarındaki sayılarında İngilizce makale yer almamaktadır. $A D E D^{\prime}$ de yayın dili İngilizce olan en fazla makale $2016(\mathrm{f}=5)$ yılında yayımlanmıştır.

\section{ADED'de Yayımlanan Makalelerin Sayfa Sayılarının Yıllara Göre Dağılımı}

$A D E D^{\prime}$ de yayımlanan makalelerin sayfa sayılarının dağılımları incelenmiştir. İnceleme sonucunda elde edilen veriler yıllara göre dört grupta toplanmıştır.

Tablo 4. ADED'de yayımlanan makalelerin sayfa sayılarının yıllara göre dağılımı

\begin{tabular}{ccccccccc}
\hline Sayfa Aralıkları & $\mathbf{2 0 1 3}$ & $\mathbf{2 0 1 4}$ & $\mathbf{2 0 1 5}$ & $\mathbf{2 0 1 6}$ & $\mathbf{2 0 1 7}$ & $\mathbf{2 0 1 8}$ & Toplam & $\%$ \\
\hline 4-10 sayfalı makale sayısı & 13 & 3 & 3 & 3 & 7 & 1 & 30 & 12 \\
\hline 11-15 sayfalı makale sayısı & 11 & 12 & 9 & 22 & 16 & 14 & 84 & 33 \\
\hline 16-20 sayfalı makale sayısı & 7 & 8 & 10 & 12 & 19 & 31 & $\mathbf{8 7}$ & $\mathbf{3 4}$ \\
\hline 21+ sayfalı makale sayısı & 1 & 7 & 3 & 4 & 16 & 22 & 53 & 21 \\
\hline Toplam Makale Sayısı & 32 & 30 & 25 & 41 & 58 & 68 & 254 & 100 \\
\hline
\end{tabular}


Tablo 4'e göre $A D E D^{\prime}$ de yayımlanan makalelerin sayfa aralığına bakıldığında 16-20 sayfa aralığının en yüksek (\%34) olduğu görülmektedir ( $f=87$ ). Sayfa aralığı bakımından ikinci en yüksek oran \%33 ile 11-15 sayfa aralığıdır ( $f=84)$.

Derginin ilk yayım yılında en fazla makale 4-10 sayfa aralığında (\%12) yer almaktadır. Son yayım yılı olan 2018 'de ise en az makale 4-10 sayfa aralığında verilmiştir. Bu bulgu derginin zaman içerisinde sayfa hacmi bakımından daha kapsamlı yayınlara yer verdiğini ortaya koymaktadır.

2013'ten itibaren 6 cilt ve her cilt 4 sayı olarak yayımlanan derginin ciltlerinin sayfa sayıları ise sırayla şu şekildedir: 1. Cilt: 384 sayfa, 2. Cilt: 494 sayfa, 3. Cilt: 413 sayfa, 4. Cilt: 638 sayfa, 5. Cilt: 999 sayfa ve 6. Cilt: 1323 . Sonuç olarak dergi her geçen yıl daha fazla sayfa sayısına sahip olarak yayımlanmıştır. Ancak 3. Cilt bir önceki senenin sayfa sayısına ulaşamamış ve daha kısa olarak yayımlanmıştır.

ADED'de Yayımlanan Makalelerin Yazarlık Durumlarına Göre Dağııımı

$A D E D^{\prime}$ de yayımlanan makalelerin yazar kadroları nicelik olarak incelenerek ulaşılan veriler aşağıda gösterilmiştir.

Tablo 5. ADED'de yayımlanan makalelerin yazarlık durumlarına göre dağılımı

\begin{tabular}{lrrrrrrr}
\hline Yazarlık Durumları & $\mathbf{2 0 1 3}$ & $\mathbf{2 0 1 4}$ & $\mathbf{2 0 1 5}$ & $\mathbf{2 0 1 6}$ & $\mathbf{2 0 1 7}$ & $\mathbf{2 0 1 8}$ & Toplam \\
\hline Tek yazarlı makale sayısı & 13 & 14 & 7 & 20 & 25 & 32 & 111 \\
\hline Iki yazarlı makale sayısı & 15 & 13 & 17 & 19 & 29 & 29 & $\mathbf{1 2 2}$ \\
\hline Üç yazarlı makale sayısı & 3 & 3 & 1 & 2 & 1 & 6 & 16 \\
\hline Dört yazarlı makale sayısı & 1 & - & - & - & 3 & 1 & 5 \\
\hline Toplam Makale Sayısı & & & & & & $\mathbf{2 5 4}$ \\
\hline
\end{tabular}

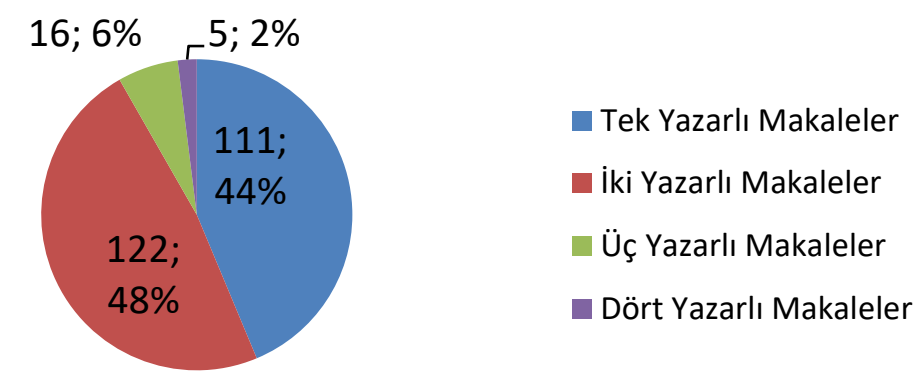

Grafik 1. $A D E D^{\prime}$ de Yayımlanan Makalelerin Yazarlık Durumlarının Yüzdelik Dağılımı

Yukarıdaki tablo ve grafikte $A D E D^{\prime}$ de yayımlanan makalelerin yazar kadrolarına ilişkin bilgiler verilmektedir. Buna göre $A D E D^{\prime}$ de yayımlanan makalelerin yazar kadroları içinde oranı en yüksek olan 
yazar grubu, iki yazarlı makalelerdir $(f=122)$. İki yazarlı makaleleri, tek yazarlı makaleler $(f=111)$ takip etmektedir. Yazarlık durumları içinde dört yazarlı makalelerin $(f=5)$ en az olduğu görülmektedir.

Yazar sayılarına bakıldığında makalelerin \%48'sinin iki yazarlı, \%44’ünün ise tek yazarlı olduğu belirlenmiştir. Yayımlanan makalelerin $\% 56$ 'sı çok yazarlıdır. Buna göre dergide çok yazarlı yayın yapma eğiliminin güçlü olduğu görülmektedir.

\section{ADED'de Yayımlanan Makalelerin Yazarlarının Kurumlara Göre Dağılımı}

$A D E D^{\prime}$ de yayımlanan makalelerin yazarlarının kurumları incelenmiştir ve ulaşılan veriler Tablo 6'da gösterilmiştir. Tabloda yazar sayısı 3 ve 3'ün üzerinde olan kurumlar verilmiştir. Yazar sayısı 1 ve 2 olan kurumlar ise "Diğer Kurumlar" başlığı altında toplanmıştır.

Tablo 6. ADED'de yayımlanan makalelerin yazarlarının kurumlara göre dağılımı

\begin{tabular}{|c|c|c|c|}
\hline Kurum Adı & Yazar Sayısı & Kurum Adı & Yazar Sayısı \\
\hline Gazi Üniversitesi & 45 & Necmettin Erbakan Üniversitesi & 5 \\
\hline MEB & 32 & Giresun Üniversitesi & 5 \\
\hline Abant İzzet B. Üniversitesi & 28 & Bartın Üniversitesi & 5 \\
\hline Mustafa Kemal Üniversitesi & 26 & 19 Mayıs Üniversitesi & 5 \\
\hline Çanakkale 18 Mart Üniversitesi & 26 & Gaziosmanpaşa Üniversitesi & 4 \\
\hline Yıldız Teknik Üniversitesi & 18 & Düzce Üniversitesi & 4 \\
\hline İstanbul Aydın Üniversitesi & 12 & Mehmet Akif Ersoy Üniversitesi & 4 \\
\hline Sakarya Üniversitesi & 12 & Erzincan Üniversitesi & 4 \\
\hline İnönü Üniversitesi & 11 & Pamukkale Üniversitesi & 4 \\
\hline Karadeniz Teknik Üniversitesi & 10 & Cumhuriyet Üniversitesi & 4 \\
\hline Muğla Sıtkı K. Üniversitesi & 10 & R. Tayyip Erdoğan Üniversitesi & 3 \\
\hline Ordu Üniversitesi & 10 & Kırşehir Ahi Evran Üniversitesi & 3 \\
\hline Gaziantep Üniversitesi & 9 & Erciyes Üniversitesi & 3 \\
\hline Ankara Üniversitesi & 8 & Amasya Üniversitesi & 3 \\
\hline Dumlupınar Üniversitesi & 8 & Kilis 7 Aralık Üniversitesi & 3 \\
\hline Atatürk Üniversitesi & 7 & İstanbul Üniversitesi & 3 \\
\hline Kırıkkale Üniversitesi & 7 & Yanya Üniversitesi (Yunanistan) & 3 \\
\hline Bülent Ecevit Üniversitesi & 7 & Aksaray Üniversitesi & 3 \\
\hline Uludağ Üniversitesi & 7 & Yüzüncü Yıl Üniversitesi & 3 \\
\hline Hacettepe Üniversitesi & 5 & Diğer Kurumlar(32 Kurum) & 43 \\
\hline Toplam Kurum Sayısı & & & 71 \\
\hline
\end{tabular}


2013 yılından itibaren dergiye 71 farklı kurumdan makale gönderildiği belirlenmiştir. 2 makale sahibinin ise kurumu belirtilmeyip "bağımsız araştırmacı/bilim uzmanı" tanımı kullanılmıştır. Makale gönderilen kurumların 62'sinin (\%88) yurt içi; 8'inin (\%12) ise yurt dışı adresli olduğu görülmüştür.

Tablo 6 incelendiğinde $A D E D$ 'e en çok makale gönderen kurumun Gazi Üniversitesi ( $f=45$ ) olduğu belirlenmiştir. Gazi Üniversitesi'ni sırasıyla MEB ( $f=32)$, Abant İzzet Baysal Üniversitesi ( $f=28$ ) takip etmektedir.

\section{ADED'de Yayımlanan Makalelerin Yazar Unvanlarının Sayısal Dağılımı}

$A D E D^{\prime}$ de yayımlanan makalelerin yazar unvanlarının dağııımı incelenmiştir ve ulaşılan veriler Tablo 7'de gösterilmiştir. Unvan sıralaması oluşturulurken 2017 yılında YÖK tarafından yapılan değişiklik göz önüne alınarak Yrd. Doç. Dr. unvanı Dr. Öğr. Üyesi unvanı ile birlikte incelenmiştir.

Tablo 7. ADED'de yayımlanan makalelerin yazarunvanlarının sayısal dağılımı

\begin{tabular}{lrrrrrrr}
\hline Unvanlar & $\mathbf{2 0 1 3}$ & $\mathbf{2 0 1 4}$ & $\mathbf{2 0 1 5}$ & $\mathbf{2 0 1 6}$ & $\mathbf{2 0 1 7}$ & $\mathbf{2 0 1 8}$ & Toplam \\
\hline Prof. Dr. & 8 & 2 & 1 & 4 & 6 & 7 & 28 \\
\hline Doç. Dr. & 11 & 10 & $\mathbf{1 4}$ & 13 & 18 & 25 & 91 \\
\hline Dr. Öğr. Üyesi/Yrd. Doç. Dr. & $\mathbf{1 7}$ & $\mathbf{1 2}$ & 9 & $\mathbf{1 7}$ & $\mathbf{2 9}$ & $\mathbf{2 6}$ & $\mathbf{1 1 0}$ \\
\hline Öğr. Gör. Dr. & - & - & - & 5 & - & 6 & 11 \\
\hline Dr. Arş. Gör. & - & - & - & - & 1 & 5 & 6 \\
\hline Dr. & - & 3 & 2 & 8 & 6 & 5 & 24 \\
\hline Öğr. Gör. & 3 & 2 & - & - & 3 & 4 & 12 \\
\hline Arş. Gör. & 8 & 10 & 8 & 8 & 8 & 13 & 55 \\
\hline Okutman & 2 & 5 & 1 & - & 2 & 2 & 12 \\
\hline Öğretmen & 3 & 2 & 2 & 1 & 9 & 4 & 21 \\
\hline Doktora Öğrencisi & 1 & 1 & 1 & 5 & 3 & 5 & 16 \\
\hline Yüksek L. Öğrencisi & - & 2 & 4 & 1 & 8 & 7 & 22 \\
\hline Toplam & & & & & 408 \\
\hline
\end{tabular}

Tablo 7'ye göre $A D E D^{\prime}$ de en çok Dr. Öğr. Üyesi /Yrd. Doç. Dr. unvanlı yazarların makaleleri yayımlanmıştır. Dr. Öğr. Üyesi /Yrd. Doç. Dr. unvanlı yazarları sırasıyla Doç. Dr. (f=91), Arş. Gör. (f=55) unvanlı yazarlar takip etmektedir.

$A D E D$ 'de bugüne kadar toplam 408 unvan ile makale yayımlanırken; 4.ciltte "ilgili yazar", 5.ciltte "uzman" ve 6.ciltte "bilim uzmanı" ve "uzman" ifadeleri unvan olarak kullanılmıştır. Ayrıca 5 yazarın unvanına makale içinde yer verilmemiş ve elde bulunan verilerle (isim, kurum bilgisi) unvan bilgisine ulaşılamamıştır. 
ADED'de Yayımlanan Makalelerin Değerlendirme Sürelerinin Sayısal Dağılımı

$A D E D^{\prime}$ de yayımlanan makalelerin değerlendirilme süresi incelenerek veriler Tablo $8^{\prime}$ de gösterilmiştir. Bu kapsamda yapılan incelemede 2013 ve 2014 yıllarında yayımlanan makalelerin değerlendirme sürelerinin belirtilmediği görülmüştür. Ayrıca 2015 yılında yayımlanan 3. Cilt 1. Sayıda da makale değerlendirme süresine ilişkin bilgi yer almamaktadır.

Tablo 8. ADED'de yayımlanan makalelerin değerlendirme sürelerinin sayısal dağılımı

\begin{tabular}{ccrrrrrr}
\hline Değerlendirme Süresi & $\mathbf{2 0 1 3}$ & $\mathbf{2 0 1 4}$ & $\mathbf{2 0 1 5}$ & $\mathbf{2 0 1 6}$ & $\mathbf{2 0 1 7}$ & $\mathbf{2 0 1 8}$ & Toplam \\
\hline 1 Ay & - & - & $\mathbf{9}$ & 6 & 16 & 20 & 51 \\
\hline 1-3 Ay & - & - & 8 & $\mathbf{2 6}$ & $\mathbf{4 2}$ & $\mathbf{3 9}$ & $\mathbf{1 1 5}$ \\
\hline 4-6 Ay & - & - & 2 & 8 & - & 7 & 17 \\
\hline 7-9 Ay & - & - & - & 1 & - & 2 & 3 \\
\hline Toplam Makale Sayısı & & & & & & & 186 \\
\hline
\end{tabular}

Tablo 8'e göre $A D E D^{\prime}$ de yayımlanan makalelerin $\% 73$ 'ünün değerlendirme süresinin belirtildiği görülmektedir. Makalelerin \%27'sinin değerlendirme süresi bilgisine ulaşılamamıştır. Elde edilen verilere göre, yayımlanan makalelerin büyük çoğunluğu 1-3 Ay ( $f=115)$ içerisinde değerlendirilmektedir. Bunu 1 Ay $(f=51)$ ve 4-6 Ay ( $f=17)$ içinde değerlendirilen makaleler takip etmektedir.

$A D E D^{\prime}$ de en uzun makale değerlendirme süresi 8 ay 5 gündür. Bu makale Nisan 2018 (6/2) sayısında yayımlanmıştır. Dergide en kısa makale değerlendirme süresi ise 6 gün olarak tespit edilmiştir. Bu makale Temmuz 2017 (5/3) sayısında yer almaktadır.

\section{ADED'de Yayımlanan Makalelerde Kullanılan Kaynak Türleri}

$A D E D^{\prime}$ de yayımlanan makalelerin kaynakçalarında kullanılan kaynak türlerinin dağııımı aşağıda gösterilmiştir.

Tablo 9. ADED'de yayımlanan makalelerin kaynakçalarında kullanılan kaynak türlerinin dağılımı

\begin{tabular}{ll}
\hline Dergi (Makale) & 3016 \\
\hline Kitap & 2460 \\
\hline Tez & $\mathbf{8 4 5}$ \\
\hline Diğer (Ders kitabı, rapor, sözlük, toplantı notları vb.) & 402 \\
\hline Kitap içinde bölüm & 367 \\
\hline İnternet kaynakları & $\mathbf{3 1 1}$ \\
\hline Bildiri kitabı & $\mathbf{2 1 7}$ \\
\hline Elektronik kaynak & $\mathbf{8 6}$ \\
\hline Toplam & $\mathbf{7 7 0 4}$ \\
\hline
\end{tabular}




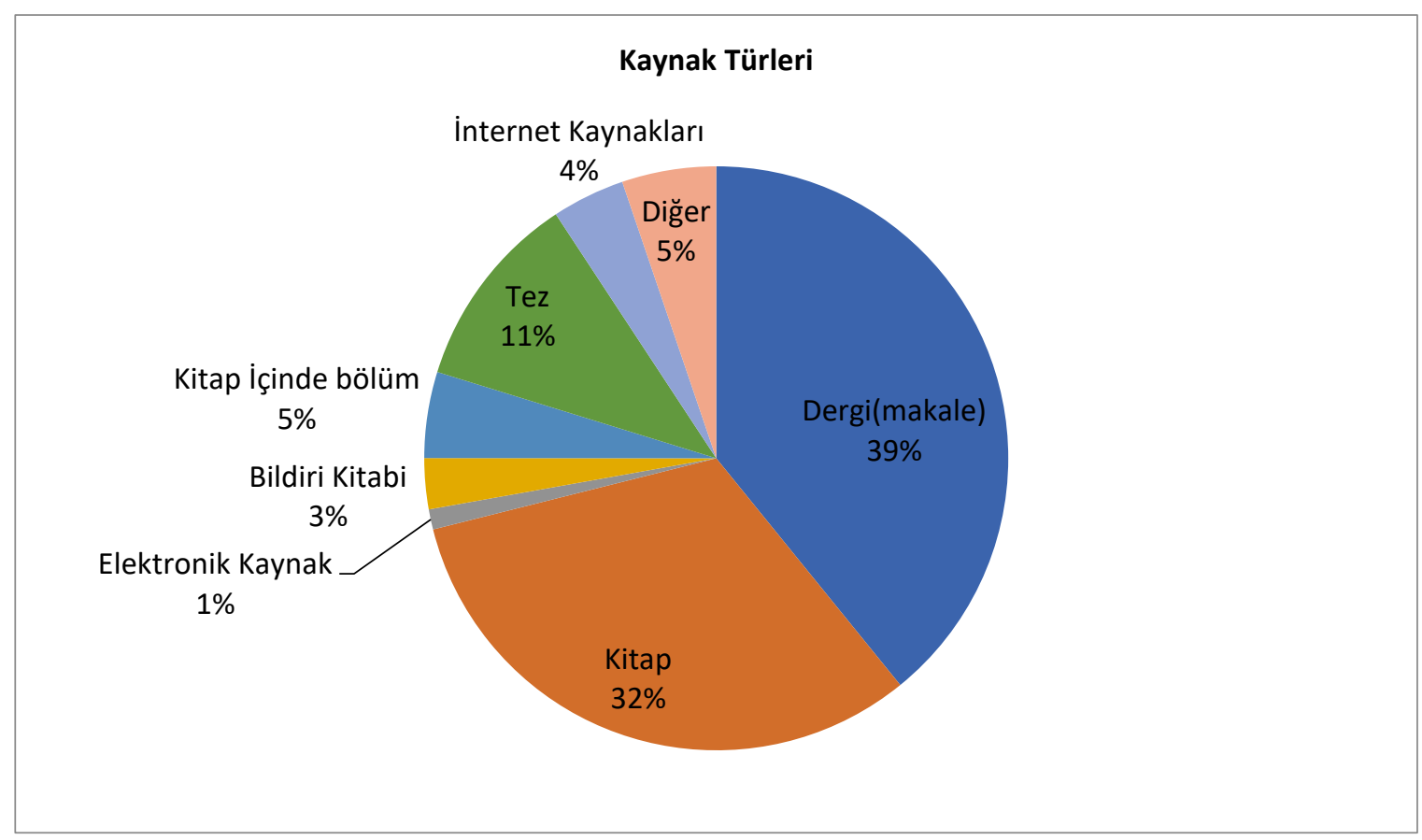

Grafik 2. $A D E D^{\prime}$ de Yayımlanan Makalelerin Kaynakçalarında Kullanılan Kaynak Türleri

Yukarıdaki tablo ve grafikte $A D E D^{\prime}$ de yayımlanan makalelerdeki toplam kaynak türü sayıları verilmiştir. Buna göre $A D E D^{\prime}$ de yayımlanan makalelerdeki toplam kaynak türü sayısının 7704 olduğu görülmüştür. Dergide en sık kullanılan kaynak türü dergi (makale) $(f=3016)$ olmuştur. Bunu sırasıyla kitap $(f=2460)$ ve tez $(f=845)$ takip etmektedir.

\section{ADED'de Yayımlanan Makalelerin Kaynakça Sayılarının Yıllara Göre Dağılımı}

$A D E D^{\prime}$ de yayımlanan makalelerin kaynakça sayılarının yıllara göre dağılımı incelenerek elde edilen veriler aşağıda gösterilmiştir.

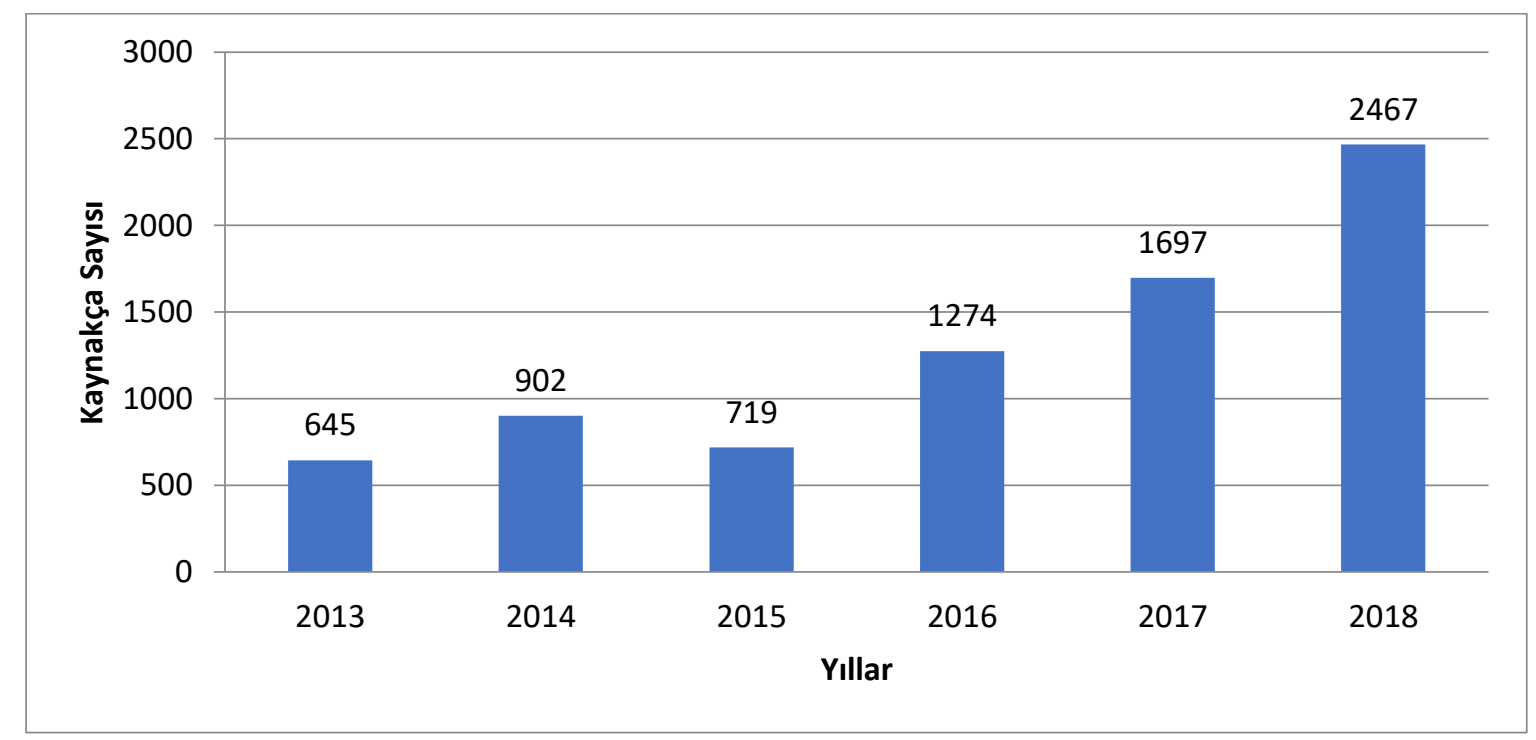

Grafik 3. ADED’de Yayımlanan Makalelerin Kaynakça Sayılarının Yıllara Göre Dağııımı 
Yukarıdaki grafikte $A D E D^{\prime}$ de yayımlanan makalelerin kaynakça sayılarının yıllara göre dağııımı verilmiştir. Buna göre $A D E D^{\prime}$ de yayımlanan makalelerde en çok kaynakça 2018 ( $\left.\mathrm{f}=2467\right)$ yılında kullanılmıştır. Bunu sırasıyla 2017 ( $\mathrm{f}=1697)$ ve 2016 ( $\mathrm{f}=1274)$ takip etmektedir. En az kaynakça kullanılan yıl ise 2013'tür ( $f=645)$.

ADED'de Yayımlanan Makalelerin Konularının Yıllara Göre Dağııımı

$A D E D^{\prime}$ de yayımlanan makalelerin yıllara göre konu dağılımı incelenmiştir ve elde edilen veriler Tablo 10'da gösterilmiştir. Konusal analiz tablosunun oluşturulmasında Varışoğlu ve diğerlerinin (2013) sınıflandırması temel alınmıştır.

Tablo 10. ADED'de yayımlanan makalelerin konularının yıllara göre dağılımı

\begin{tabular}{|c|c|c|c|c|c|c|c|c|c|c|c|c|c|c|c|c|c|}
\hline 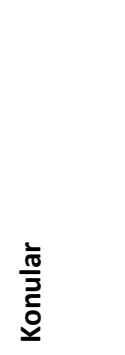 & 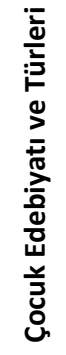 & 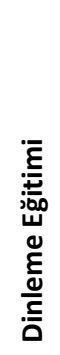 & 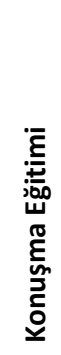 & 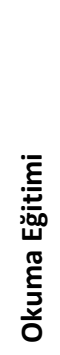 & 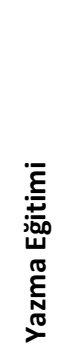 & 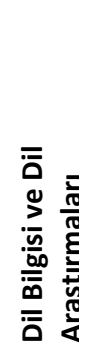 & $\begin{array}{l}\frac{5}{\pi} \\
\frac{\pi}{0} \\
\frac{\pi}{\pi} \\
\frac{5}{0} \\
\frac{2}{0}\end{array}$ & 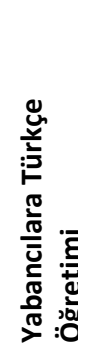 & 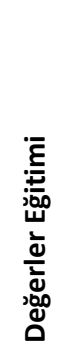 & 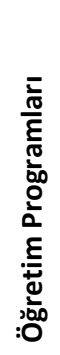 & $\begin{array}{l}\text { 兰 } \\
\overline{\bar{O}} \\
\text { 弟 }\end{array}$ & 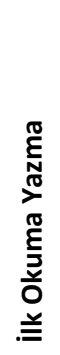 & 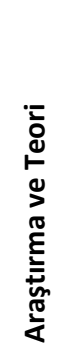 &  & 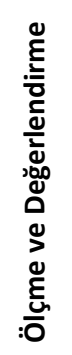 & 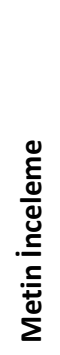 & 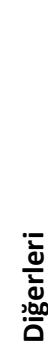 \\
\hline 2013 & 1 & - & 1 & - & - & 3 & 3 & 4 & 1 & 1 & - & - & 2 & 7 & 1 & 5 & 2 \\
\hline 2014 & - & 2 & 1 & 3 & 2 & 4 & 6 & 1 & 1 & - & - & - & - & - & 5 & 4 & 1 \\
\hline 2015 & 1 & - & - & 2 & 6 & 5 & 1 & - & 2 & - & - & - & - & 3 & - & 3 & 2 \\
\hline 2016 & 3 & 3 & 1 & 4 & 6 & 3 & 2 & 5 & 2 & 2 & 1 & - & 1 & 2 & 2 & 2 & 2 \\
\hline 2017 & - & - & 3 & 3 & 6 & 5 & 6 & 5 & 3 & 3 & 3 & 3 & 2 & 5 & 1 & 5 & 2 \\
\hline 2018 & 5 & - & 4 & 12 & 6 & 6 & 3 & 10 & 3 & 2 & 1 & 3 & 1 & 3 & 2 & 6 & 2 \\
\hline Toplam & 10 & 5 & 10 & 24 & 26 & 26 & 21 & 25 & 12 & 8 & 5 & 6 & 6 & 20 & 11 & 25 & 11 \\
\hline
\end{tabular}

Tablo $10^{\prime}$ da yer alan verilere göre $A D E D^{\prime}$ de yayımlanan makalelerde en çok çalışılan konular Dil Bilgisi ve Dil Araştırmaları ile Yazma Eğitimi $(f=26)$ olmuştur. Bunu Yabancılara Türkçe Öğretimi ile Metin İnceleme $(f=25)$ konuları takip etmektedir. Makalelerde en az çalışılan konular ise Dinleme Eğitimi ve Çok Dillilik'tir $(f=5)$.

Dil Bilgisi ve Dil Araştırmaları, Ders Kitapları, Değerler Eğitimi ve Metin İnceleme konuları her yıl araştırılan konular olmaları bakımından önem taşımaktadırlar.

\section{Tartışma, Sonuç ve Öneriler}

Bilimsel iletişim sürecinde akademik yayınlar bibliyometrik ölçevler kullanılarak incelenebilir. Bibliyometrik çalışmalar alana özgü bilimsel dergilerin tanıtımı, akademik alanın yapısı hakkında bilgi aktarımı açısından son derece önemlidir. Bu çalışmada Ana Dili Eğitimi dergisinde yayımlanan makalelerin bibliyometrik parametrelerle incelenmesi, eğilimlerinin ortaya konması ve gösterdiği gelişim profilinin çıkarılması amaçlanmıştır. Bu bağlamda dergideki akademik yayın türleri, makalelerin yayın dili, makalelerin sayfa sayıları, makalelerin yazarlık durumları, yazarların çalıştıkları 


\section{Ana Dili Eğitimi Dergisinde Yayımlanan Makalelerin Bibliyometrik Analizi}

kurumlar, yazarların unvanı, makalelerin değerlendirme süresi, makalelerde kullanılan kaynak türlerinin dağılımı, makalelerdeki kaynakça sayıları, makalelerin konu dağılımı gibi bibliyometrik göstergeler incelemeye tabi tutulmuştur.

2013 yılından beri yayın hayatına devam eden ADED; Ocak, Nisan, Temmuz ve Ekim olmak üzere yılda dört defa yayımlanmaktadır. Beş yıllık süreç içinde dergide toplam 251 makale ve 3 kitap tanıtımı yayımlanmıştır. Dergide yayımlanan makale sayısı, 2014 ve 2015 yılları dışında, her yıl artarak devam etmiştir. Buna karşılık kitap tanıtım yazılarının çok az olduğu görülmüştür. Bilimsel dergiler, alana ilişkin çalışmaların yayımlandığı ve yeni yayınların tanıtıldığı akademik ortamlardır. Bu yanıyla alandaki bilimsel iletişimin artmasına katkı sağlamaktadır. Dolayısıyla $A D E D^{\prime}$ de daha fazla sayıda kitap tanıtım yazısına yer verilmesi önemli görülmektedir.

Yayın sayıları analizi sonucunda Ana Dili Eğitimi Dergisinin ilk üç yılında alanda tanınmaya başladığı ve sonraki yıllarda akademik yayınlar için daha çok tercih edilen bir noktaya ulaştığı görülmektedir. Bu bağlamda $A D E D$ 'in Türkçe eğitimi akademik alanının kurumsallaşma sürecinde etkin bir rol oynayarak alandaki bilimsel etkileşimin artmasına katkıda bulunduğunu belirtmek mümkündür.

$A D E D^{\prime}$ de derginin birincil yayın dilinin Türkçe, uluslararası niteliği ve diğer ulusal dillerin eğitimi ile ilgili yayınlara açık olması münasebetiyle de ikinci yayın dilinin İngilizce olduğu belirtilmiştir (Karadağ, 2013). Buna göre yayın dili bazlı karşılaştırmalarda, dergide yayımlanan araştırmaların büyük bölümünü Türkçe yazıımış makalelerin oluşturduğu; İngilizce yazılmış makalelerin ise az sayıda olduğu görülmektedir. Dergide Türkçe yayımlanan makale sayısının İngilizce makalelere göre daha fazla olmasının sebebi, derginin Türkçenin eğitimi-öğretimi alanına odaklanmış olması olabilir.

Çalışmada kullanılan diğer bir parametre yayınların sayfa sayılarıdır. Bulgulara göre beş yıllık süreç içinde yayımlanan makalelerin toplam 4251 sayfa olduğu belirlenmiştir. Yayımlanan makalelerin sayfa sayılarının en az 4; en fazla 40 olduğu görülmüştür. Bir makalenin ortalama sayfa sayısı 16,73'tür. Makale sayfa sayıları üzerinde derginin Yazım Kuralları'nda belirtilen "Metin uzunluğu (başlıklar, özet, İngilizce özet (abstract), metin, tablolar ve kaynakça dâhil) 5500 sözcüğü geçmemelidir." ibaresinin birinci derecede etkili olduğu düşünülmektedir.

Makalelerin yazar sayıları incelendiğinde iki yazarlı makalelerin çoğunlukta olduğu sonucuna ulaşımıştır. Bu açıdan dergiye katkı sağlayan araştırmacıların ortak yayın yapma eğiliminde olduğunu belirtmek mümkündür. Üç ve dört yazarlı makale sayılarının azlığı ise Varışoğlu ve diğerlerinin (2013) bulguları ile koşutluk göstermektedir. Buna göre Türkçe eğitimi araştırmalarında grup çalışmasının getireceği iş yükü ve sorumluluklardan kaçınma durumunun devam ettiği görülmektedir. 
Dergiye katkı sağlayan kurumlar incelendiğinde 71 farklı kurumdan makalenin yayımlandığı ve 2 makale sahibinin bağı bulunduğu kurumun belirtilmeyip "bağımsız araştırmacı/bilim uzmanı" tanımı kullanıldığı saptanmıştır. Makale gönderen kurum bazlı karşılaştırmalarda, dergiye gönderilen makalelerin büyük bölümünü yurt içi adresli kurumlar oluşturmaktadır. Bu bulgu derginin ulusal boyutunu göstermesi bakımından önemlidir. $A D E D^{\prime}$ e en çok katkı sağlayan ilk üç kurum sırayla Gazi Üniversitesi, MEB ve Abant İzzet Baysal Üniversitesi'dir. MEB'in ikinci sırada yer alması derginin sadece üniversitelerle sınırlı kalmadığının önemli bir göstergesidir. ADED, Gazi Üniversitesi ve Ankara Üniversitesi gibi köklü üniversitelerden araştırmalara ev sahipliği yaptığı gibi Bartın Üniversitesi, Aksaray Üniversitesi gibi 2006 ve sonrasında kurulan genç üniversitelerdeki araştırmacılar tarafından da tercih edilmektedir. Bu durum derginin ulusal boyutta geniş bir akademik yelpazeye sahip olduğunu göstermektedir.

Çalışmada dergiye makale gönderen yazarların unvan dağılımına bakılmıştır. 2013-2018 yılları arasında dergiye en çok katkı sağlayan akademisyenlerin Dr. Öğr. Üyesi/Yrd. Doç. Dr. unvanlı araştırmacılar olduğu görülmüştür. $A D E D^{\prime}$ in ULAKBiM TR Dizin tarafından taranan hakemli bir dergi olması ve burada yayımlanan makalenin Doçentlik Değerlendirme Kriterlerine uygun olması bu kariyer basamağındaki yığımayı açıklamaya yardımcı olmaktadır. Dr. Öğr. Üyesi/Yrd. Doç. Dr. unvanlı araştırmacıları sırasıyla Doç. Dr. ve Arş. Gör. unvanlı yazarlar takip etmektedir. En az katkı ise doktora öğrencileri tarafından verilmiştir. Ayrıca 4.ciltte "ilgili yazar", 5.ciltte "uzman" ve 6.ciltte "bilim uzmanı" ve "uzman" ifadeleri unvan olarak kullanılmıştır. Bunların dışında 5 yazarın unvanına makale içinde yer verilmemiş ve elde bulunan verilerle (isim, kurum bilgisi) unvan bilgisine ulaşılamamıştır. Bu bulgu makale yazarlarının lisansüstü öğrenci olma olasılığını yükseltmektedir.

ADED'de yayımlanan makalelerin değerlendirilme süresine bakıldığında; 2013 ve 2014 yıllarında yayımlanan makalelerin değerlendirme sürelerinin belirtilmediği görülmüştür. Ayrıca 2015 yılında yayımlanan 3. Cilt 1. Sayıda da makale değerlendirme süresine ilişkin bilgi yer almamaktadır. 2015 tarihi itibariyle $A D E D^{\prime}$ in ULAKBIM TR Dizin tarafından taranmaya başlanmasına bağlı olarak, yayımlanan makalelerde "Geliş" ve "Kabul" başlığı ile tarihler verilmeye başlanmıştır. Dergiye gönderilen makalelerin \%73'ünün değerlendirme süreleri belirtilmiş olup, bunlardan $\% 62$ 'sinin 1-3 ay arasında kabul sürecinin gerçekleştiği belirlenmiştir.

Çalışma kapsamında 2013-2018 yılları arasında yayımlanmış olan 254 akademik araştırmanın kaynaklar bölümü incelenmiş ve kaynak türlerinin ayrımı yapılmıştır. Bulgulara göre toplam atıf sayısının 7704 olduğu görülmüştür. Dergide ağırlıklı olarak dergi (makale) türünde kaynaklar kullanıldığı belirlenmiştir. Bu durum araştırmacıların çalışmalarında daha çok hakem denetiminden geçmiş kaynak türlerini tercih ettiğini ortaya koymaktadır. 
Çalışma kapsamındaki makalelerin kaynakça sayılarının yıllara göre dağıımına bakıldığında; 2018 yılındaki makalelerde daha çok kaynakça kullanıldığı görülmektedir. Bu bulgu, derginin 2018'deki sayılarında daha çok makale yayımlanmasından kaynaklanıyor olabilir.

Makalelerin konularına bakıldığında; en çok çalışılan konular, Yazma Eğitimi ve Dil Bilgisi/Dil Araştırmaları konuları olmuştur. İkinci sırada ise Yabancılara Türkçe Öğretimi ve Metin İnceleme konuları gelmektedir. Buna göre son yıllarda ikinci dil olarak Türkçe öğretimine büyük önem verilmesi ve Yabancılara Türkçe öğretimi yapan yurt içi-yurt dışı kuruluşlardaki sayısal artışın bilimsel gelişmeye katkı sağladığını belirtmek mümkündür. Metin Türleri ve Metin İnceleme ise Türkçe eğitimi alanında uzun yıllardır tercih edilen araştırma konuları olmuştur. Dinleme Eğitimi ve Çok Dillilik konuları ise en az araştırma yapılan konular arasındadır. Bu bulgu, Varışoğlu ve diğerleri (2013) ile Mutlu'nun (2018) yapmış olduğu çalışmaların sonuçlarıyla koşutluk göstermektedir.

Konu dağılım tablosu incelendiğinde temel dil becerilerine eşit derecede önem verilmediği görülmektedir. Buna göre dergide Yazma ve Okuma eğitimi çalışmalarına yoğun olarak rastlanmaktadır. Diğer taraftan Konuşma Eğitimi ve Dinleme Eğitimi konularında daha az çalışma bulunmaktadır. Buna gerekçe olarak uygulamanın zorluğu, değerlendirmenin gözlemi de içermesi gösterilebilir (Varışoğlu ve diğerleri, 2013).

Sonuç olarak Ana Dili Eğitimi Dergisi ile ilgili şu genel bilgilere ulaşılmıştır: $A D E D$ yayımlanmış toplam 24 sayıda 254 bilimsel çalışmayı akademik ağ ile buluşturmuştur. Dergide en çok yer verilen akademik yayın türü, makaledir. Yayımlanan makalelerin yayın dili ağırlıklı olarak Türkçedir. Makale uzunluğunun 16-20 sayfa aralığında yoğunlaştığı, iki yazarlı makalelerin daha fazla olduğu sonucuna ulaşıımıştır. Dergiye katkı sağlayan araştırmacıların çoğunlukla Dr. Öğr. Üyesi/Yrd. Doç. Dr. unvanında olduğu belirlenmiştir. Dergiye en çok katkıda bulunan araştırmacılar Gazi Üniversitesi adreslidir. Dergiye gönderilen makalelerin değerlendirme süreci genel olarak 1-3 ay içerisinde tamamlanmaktadır. Kaynakça incelemesi sonucuna göre en sık kullanılan kaynak türü dergidir (makale). Dergideki makalelerde en çok kaynakça 2018 yılında yayımlanan sayılarda kullanılmıştır. Konu dağılımına göre dergide en çok Yazma Eğitimi ve Dil Bilgisi/Dil Araştırmaları konuları çalışıımıştır. En az çalışılan konular ise Dinleme Eğitimi ve Çok Dillilik'tir. Temel dil becerilerine gösterilen ilginin eşit olmadığı, bunun sebebinin Dinleme ve Konuşma Eğitimi çalışmalarının daha zorlu bir süreç gerektirmesi olabileceği düşünülmektedir.

Bu çalışma Türkçe eğitimi akademik alanında ilk bilimsel dergi olan Ana Dili Eğitimi Dergisinin beş yıllık süreçteki (2013-2018) bibliyometrik profilini ortaya koymayı hedefleyen bir araştırmadır. Bundan sonraki ikinci beş yıllık süreçte benzer bir çalışmanın yeniden yapılması derginin bilimsel 
gelişimini ve performansını izlemek açısından hem alanyazına hem de bilim insanlarına katkı sağlayabilir.

\section{Kaynaklar}

Al, U. (2012). Türk Kültürü ve Hacı Bektaş Veli Araştırma Dergisi, 2008-2010. Türk Kültürü ve Hacı Bektaş Veli Araştırma Dergisi, 61, 273-286.

Al, U., ve Coştur, R. (2007). Türk Psikoloji Dergisi'nin bibliyometrik profili. Türk Kütüphaneciliği, 21(2), 142-163.

Al, U.,Soydal, İ., ve Yalçın, H. (2010). Bibliyometrik özellikleri açısından Bilig'in değerlendirilmesi. bilig, 55, 1-20.

Armutlu, C., ve Arı, G. S. (2010). Yönetim modalarının yüksek lisans ve doktora tezlerine yansımaları: Bibliyometrik bir analiz. METU Studies in Development, 37(1), 1-25.

Beşel, F. ve Yardımcıoğlu, F. (2017). Maliye Dergisi'nin bibliyometrik analizi: 2007-2016 Dönemi. Maliye Dergisi, $172,133-151$.

Birinci, H. G. (2008). Turkish Journal of Chemistry'nin bibliyometrik analizi. Bilgi Dünyası, 9(2), 348-369.

Cevizkaya, G.,illsay, S., ve Avcıkurt, C. (2014). Turizm alan yazınında engelliler ile ilgili çalışmaların bibliyometrik profili(2000-2013). Gazi Üniversitesi Turizm Fakültesi Dergisi, 2, 101-108.

Çetinkaya Bozkurt, Ö., ve Çetin, A. (2016). Girişimcilik ve Kalkınma Dergisi'nin bibliyometrik analizi. Girişimcilik ve Kalkınma Dergisi, 11(2), 229-263.

Çiçek, D. ve Kozak, N.(2012). Anatolia: Turizm Dergisi'nde Yayımlanan hakem denetimli makalelerin bibliyometrik profili. Türk Kütüphaneciliği, 26(4), 734-756.

Hotamışlı, M., ve Erem, I. (2014). Muhasebe ve Finansman Dergisi'nde yayınlanan makalelerin bibliyometrik analizi. Muhasebe ve Finansman Dergisi, 63, 1-20.

Karadağ, Ö. (2013). Takdim. Ana Dili Eğitimi Dergisi, 1(1),http://www.anadiliegitimi.com/issue/1359/16013 adresinden erişildi.

Karagöz, D., ve Kozak, N. (2014). Anatolia Turizm Araştırmaları Dergisi'nin bibliyometrik analizi: Araştırma konuları ve kurumlar arası iş birliğinin sosyal ağ analizi ile incelenmesi. Türk Kütüphaneciliği, 28(1), 4761.

Mutlu, H. H. (2018). Ana Dili Eğitimi Dergisinde yayınlanan araştırmaların eğilimleri: İçerik analizi. Ana Dili Eğitimi Dergisi, 6(4), 1196-1209.

Özel, Ç. H., ve Kozak, N. (2012). Turizm pazarlaması alanının bibliyometrik profili (2000-2010) ve bir atıf analizi çalışması. Türk Kütüphaneciliği, 26(4), 715-733.

Özsoy, Z. ve Demir, E. (2018) Which bariatric procedure Is the most popular in the world? A bibliometric comparison, ObesitySurgery, 28(8), 2339-2352.

Polat, C., Sağlam, M., ve Sarı, T. (2013). Atatürk Üniversitesi İktisadi ve İdari Bilimler Dergisi'nin bibliyometrik analizi. Atatürk Üniversitesi Iktisadi ve Idari Bilimler Dergisi, 27(2), 273-287.

Pritchard, A. (1969). Statistical bibliography or bibliometrics?.Journal of Documentation, 24, 348-349.

Taşkın, Z., ve Çakmak, T. (2010). Başlangıcından bugüne Bilgi Dünyası Dergisi'nin bibliyometrik profili. Bilgi Dünyası, 11(2), 332-348.

Tsay, M. Y., ve Shu, Z. Y. (2011). Journal bibliometric analysis: a case study on the Journal of Documentation. Journal of Documentation, 67(5), 806-822.

Ulu, S., ve Akdağ, M. (2015). Dergilerde yayınlanan hakem denetimli makalelerin bibliyometrik profili: Selçuk İletişim Örneği. Selçuk Iletişim, 9(1), 5-21.

Van Raan, A. F. (2003). The use of bibliometric analysis in research performance assessment and monitoring of interdisciplinary scientific developments. Technology Assessment-Theory and Practice, 1(12), 20-29. 
Varışoğlu, B., Şahin, A., ve Göktaş, Y. (2013). Türkçe eğitimi araştırmalarında eğilimler. Kuram ve Uygulamada Eğitim Bilimleri, 13(3), 1767-1781.

Yalçın, H. (2010). Millî Folklor dergisinin bibliyometrik profili (2007-2009). Millî Folklor, 22(85), 205-211.

Yalçın, H. ve Öztürk, T. (2017). Bilimsel yayınlarıyla Gazi Yaşargil. TÜBA Günce. 104-107.

\section{Extended Abstract \\ Introduction}

Scientific journals are one of the main channels in the production and dissemination of Scientific knowledge. Scientific journals allow scientists to share information and findings obtained by experiment, travel and observation with academic media. In other words, scientists publish Scientific knowledge and research in Scientific journals. In this way, a field of communication and interaction occurs in the Scientific world. Therefore, Scientific journals are decisive for the continuation of Scientific world and Scientific exchange.

Method

This research was conducted on the basis of qualitative research approach. In this study, bibliometric analysis was applied to qualitative research techniques. Bibliometric analysis is a method of numerical analysis that enables the application of mathematical and Statistical methods to books and other communication tools (Pritchard, 1969). By studying bibliometric researches and certain features of publications, it is possible to obtain various findings related to scientific communication (Al, Soydal, and Yalçın, 2010). Bibliometric methods provide high quality, reliable and informative data in the research appraisal application to evaluate the performance of publications and to follow, rank and map authors and institutions (Özsoy and Demir, 2018). Bibliometric data andanalyzesprovideinformationaboutthescientificorientationanddynamism of a journal and its participation in national and international Science and technology (Van Raan, 2003).

Result and Discussion

Bibliometric studies are very important in the context of introducing Scientific journals specific to the field, giving graduate students and researchers a perspective on the structure of the academic field. With bibliometric methods, any are a specific publication will be better known and introduced. In this study, it is aimed to examine the articles published in the Journal of Mother Language Education with bibliometric parameters, to reveal the specific trends of the journal and to drawout the development profile that has been shown since the beginning. In this context, the total number of articles in the journal, the publication language of thearticles, the page numbers of the articles, theauthorshipstatus of the articles, the institutions where the authors work, the title of the authors, theperiod of evaluation of the articles, the number of domestic and foreign citations in the articles, the topic distribution of the articles, the most published authors subject to review.

Since 2013, JOMTE has been published fou rtimes a year in January, April, July and October. A total of 251 articles and 3 book presentations were published in the journal within 5 years. The number of article spublished in the journal increased every year except 2014 and 2015. In the first three years of the journal, it has become known in the field and in later years it has reached a more preferred point for academic publications.

In JOMTE, the second language of publication is indicated in English as the primary publication language of the journal is Turkish and at the same time it is open to publications on the international character and education of other national languages (Karadağ, 2013). According to the publication language-based comparisons, the majority of the articles published in the journal were written in Turkish (96\%); Articles written in English are very limited (4\%). The number of articles published in Turkish in the journal is higher than in English articles, so the journal may be focused on the academic field of Turkish education.

Anotherparameterused in thestudy is thepagecounts of thepublications. Accordingtothefindings, thearticlespublished in 5 yearsperiodweredetermined as 4251 pages. Thenumber of publishedarticleswas at least 4 andmaximum 40 . Theaveragenumber of pages in an article is 16,73. Thetextlength (includingheadings, abstracts, abstracts, texts, tablesandreferences) should not exceed 5500 words.

This study aims to reveal the bibliometric profile of the Turkish Language Journal of Education, which is the first in the academic field of Turkish language education. It is thought that the journal will contribute to both academic and academic environment in order to monitor the academic progress of the journal between 2013-2018 and to show its Scientific development and performance. 